\title{
Association between human coronaviruses' epidemic and environmental factors on a global scale
}

\author{
Xiangyu Yan ${ }^{1} \cdot$ Zekun Wang $^{1} \cdot$ Xuechun Wang ${ }^{1} \cdot$ Xiangyu Zhang ${ }^{1} \cdot$ Lianhao Wang $^{1} \cdot$ Zuhong $^{\text {Lu }}{ }^{2} \cdot$ Zhongwei Jia $^{1,3,4}$ (D)
}

Received: 28 July 2021 / Accepted: 8 September 2021 / Published online: 5 October 2021

(C) The Author(s), under exclusive licence to Springer-Verlag GmbH Germany, part of Springer Nature 2021

\begin{abstract}
Environmental factors could influence the epidemic of virus in human; however, the association remains intricate, and the evidence is still not clear in human coronaviruses ( $\mathrm{HCoVs})$. We aimed to explore and compare the associations between $\mathrm{HCoVs}$ ' epidemic and environmental factors globally. Four common $\mathrm{HCoVs}$ ' data were collected by a systematic literature review, and data of MERS, SARS, and COVID-19 were collected from the World Health Organization's reports. Monthly positive rates of common HCoVs and incidence rates of MERS, SARS, and COVID-19 were calculated. Geographical coordinates were used to link virus data and environmental data. Generalized additive models (GAMs) were used to quantitatively estimate the association of environmental factors with HCoVs' epidemic. We found that there are wide associations between $\mathrm{HCoVs}$ and environmental factors on a global scale, and some of the associations were nonlinear. In addition, COVID-19 has the most similarities in associations' direction with common HCoVs, especially for HCoV-HKU1 in four environmental factors including the significantly negative associations with average temperature, precipitation, vegetation coverage $(p<0.05)$, and the U-shaped association with temperature range. This study strengthened the relevant research evidences and provided significant insights into the epidemic rules of HCoVs in general. The similarities between COVID-19 and common HCoVs indicated that it is critically important to strengthen surveillance on common $\mathrm{HCoVs}$ and pay more attention to environmental factors' role in surveillance and early warning of HCoVs' epidemic.
\end{abstract}

Keywords Human coronavirus · Epidemic · Environmental factor $\cdot$ Meteorological factor $\cdot$ Vegetation coverage $\cdot$ Global health . One health

\section{Introduction}

Like human beings, viruses are a link in the biological chain. Human coronaviruses (HCoVs), as the name suggests, were referred to as coronavirus which can infect human. To date, a

Xiangyu Yan and Zekun Wang contributed equally to this work.

Responsible Editor: Lotfi Aleya

Zhongwei Jia

urchinjj@163.com

1 School of Public Health, Peking University, Beijing 100191, China

2 State Key Laboratory for Bioelectronics, School of Biological Science and Medical Engineering, Southeast University, Nanjing 211189, China

3 Center for Intelligent Public Health, Institute for Artificial Intelligence, Peking University, Beijing 100191, China

4 Center for Drug Abuse Control and Prevention, National Institute of Health Data Science, Peking University, Beijing 100191, China total of seven $\mathrm{HCoVs}$, classified into alpha coronavirus (alpha-CoVs, including NL63 and 229E) and beta coronavirus (beta-CoVs, including SARS-CoV-2, MERS-CoV, SARS$\mathrm{CoV}$, HKU1, and OC43), have been found globally since HCoV-229E was detected in America in 1962 (Hamre and Procknow 1966). Among them, SARS-CoV-2, SARS-CoV, and MERS-CoV are well known because of their high death rate, while NL63, 229E, HKU1, and OC43 are seldom mentioned and concerned by public due to the similarly clinical symptoms to common cold, such as runny nose, headache, fever, and cough (Su et al. 2016; Wevers and Lia 2009), even though they more often cause mild to moderate upper or lower respiratory tract illnesses all over the world.

HCoVs, similar as other viruses, is well known to survive and reproduce inside the cells, but many studies disclosed that some virus can survive for hours or even days in suitable environmental conditions outside the host. Infective H1NI virus could survive on most kinds of environmental surfaces at $4 \mathrm{~h}$, but the viral RNA could be detected over $24 \mathrm{~h}$ at temperature of $17-21^{\circ} \mathrm{C}$ and relative humidity of $23-24 \%$ 
(Greatorex et al. 2011). And infective virus of influenza B persisted for $2 \mathrm{~h}$ at room temperature and under daylight conditions, while the virus was still infectious after 1 day when mixed with respiratory mucus (Thomas et al. 2008). The survival time in environment of coronaviruses is relatively longer. SARS-CoV could retain viability for over 5 days at temperatures of $22-25^{\circ} \mathrm{C}$ and relative humidity of $40-50 \%$ on smooth surfaces (Chan et al. 2011). MERS-CoV could survive for $48 \mathrm{~h}$ at temperature of $20^{\circ} \mathrm{C}$ and relative humidity of $40 \%$ on plastic or steel surfaces (van Doremalen et al. 2013). For SARS-CoV-2, it remained viable up to 21 days on most kinds of environmental surfaces under winter conditions (Kwon et al. 2021). Unlike other HCoVs, because SARSCoV-2 mutated rapidly (Leung et al. 2021; Zhao et al. 2021; Tang et al. 2020), its ability to survive and spread in the environment might be more diverse.

Previous studies have showed the association of $\mathrm{HCoVs}$ with some kinds of environmental factors. As for common HCoVs (i.e., NL63, 229E, HKU1, and OC43), E. Anastasiou et al. (2021) found that low temperature, low relative humidity, high cloud cover, and high precipitation were linked to increased coronavirus detection rates in Essen, Germany. du Prel et al. (2009) showed similar negative association between temperature and the common HCoVs' detection rate in pediatric patients of Mainz, Germany; however, there was positive association for relative humidity with the rate, which was opposite to E. Anastasiou et al.'s (2021) study. And Li et al. (2020) indicated that relative lower temperature combined with higher relative humidity could contribute to higher common HCoVs' activity by using the literature data of 21 countries. In addition, wind speed was found to be positively associated with the common HCoVs' detection rate (du Prel et al. 2009).

For the three HCoVs that caused highly pathogenic respiratory infections, previous evidence showed that the optimum environmental temperature for SARS's epidemic was between 16 and $28^{\circ} \mathrm{C}$, and sharp change of temperature contributed to an increase of SARS cases in Hong Kong, Guangzhou (capital of Guangdong Province), Taiyuan (capital of Shanxi Province), and Beijing in China (Tan et al. 2005). And Cai et al. (2007) indicated that daily average temperature, relative humidity, and wind speed were negatively associated with secondary attack rate of SARS in mainland China. G. Gardner et al. (2019) indicated that low temperature, low humidity, high visibility, and low minimum daily wind speed and high maximum wind speed were associated with increased MERS cases in Saudi Arabia. Another study conducted in Riyadh Region, Saudi Arabia, showed opposite findings that high temperatures were associated with higher MERS incidence, while low relative humidity and low wind speed were associated with lower MERS incidence (Altamimi and Ahmed 2020). During the pandemic of COVID-19, environmental factors also showed close association. Most of the studies indicated that temperature was negatively related to the spread of COVID-19 (Irfan et al. 2021; Haque and Rahman 2020; Rosario et al. 2020; Sarkodie and Owusu 2020), while Xie et al. found a positive association of temperature and COVID-19 infection (Xie and Zhu 2020). However, nonlinear relationship between temperature and COVID-19 was also found, for an inversed U-shaped association reported by Srivastava (2021). Moreover, Ma et al. (2020) indicated a positive association of temperature variation and the death of COVID-19 in Wuhan, China. As for humidity, though most of the studies showed the negative association of humidity and transmission of COVID-19 (Srivastava 2021; Diao et al. 2020; Islam et al. 2021; Haque and Rahman 2020), Rahimi et al. (Rahimi et al. 2021) indicated that humidity yielded a positive relationship sometimes. In the study conducted in 116 countries by Nazrul Islam et al. (2021), higher wind speed was associated with lower COVID-19 incidence. Sarkodie and Owusu (2020) observed that precipitation was negatively associated with the spread of COVID-19. COVID-19's epidemic was also associated with the air quality (Domingo et al. 2020). Some studies found that the low exposure of population to air pollutants, such as $\mathrm{PM}_{10}, \mathrm{PM}_{2.5}, \mathrm{SO}_{2}, \mathrm{NO}_{2}$, and $\mathrm{CO}$, could reduce fatality rate in the COVID-19 pandemic (Coccia (2021a); Bashir et al. 2020). Moreover, studies indicated that high levels of air pollution with low wind speed were associated with more COVID-19 infection and death (Coccia 2021a, b, c, d, 2020a, b, c). Previous study indicated that visibility can also reflect air quality comprehensively (Chen and Xie 2013). Chen et al. (2020) indicated a negative association of COVID19 transmission and visibility. In addition, You and Pan (2020) showed that increased urban vegetation could slow down the spread of COVID-19 in the USA.

Moreover, due to the global pandemic caused by COVID19 , governments have adopted various prevention and control policies, which have had a great impact on COVID-19 transmission, such as non-pharmaceutical interventions (Candido et al. 2020). Therefore, some social factors, such as high healthcare expenditures (Coccia (2021e)), longer period of lockdown (Coccia (2021f)), and quick and thorough vaccination plan in society (Coccia (2021g)), could mitigate COVID19 's epidemic. Also, the above policies influenced the environmental factors, such as the reduction of concentration of air pollutants (Shen et al. 2021; Xu et al. 2020). Therefore, it is in need to consider the society and policy factors that influence the control of COVID-19 when exploring the environmental factors' effect on COVID-19's epidemic.

In summary, although it is clear that environmental factors could influence the epidemic of $\mathrm{HCoVs}_{\mathrm{s}}$, the association remains intricate, and the evidence is still inconclusive. On the one hand, the environmental factors included in the previous studies were limited, especially for precipitation's association with SARS-CoV and MERS-CoV, visibility's association with common HCoVs and SARS-CoV, and vegetation 
coverage's association with most $\mathrm{HCoVs}$ except SARS-CoV2 . And the associations between a specific environmental factor and coronavirus were often contradictory in different studies. On the other hand, study was lacking in the comparison of similarities and differences in association with environmental factors among different $\mathrm{HCoVs}$.

In this study, we systematically explored and creatively compared the association between the seven HCoVs' epidemic and environmental factors (including meteorological factors and vegetation coverage) on a global scale, which could fill in some gaps in the relevant research evidences and provide significant insights into the epidemic rules of $\mathrm{HCoVs}$ in general. And the similarities and differences between common $\mathrm{HCoVs}$ and other HCoVs that caused highly pathogenic respiratory infections (i.e., MERS-CoV, SARS-CoV, and SARS-CoV-2) in their association with the environmental factors could provide guidance for further prevention and control of severe human coronavirus diseases.

\section{Materials and methods}

\section{Sample and data}

In this study, we collected HCoVs' data and environmental data to explore the potential associations. HCoVs' data included data of common HCoVs, MERS, SARS, and COVID-19. Environmental data included meteorological data and vegetation coverage data. The data sources and collection processes were as follows (Fig. 1).

Common HCoVs data were collected through a systematic literature review. We searched PubMed, Embase, and Web of Science for literatures which reported data on laboratoryconfirmed cases of common $\mathrm{HCoVs}$ infection on 1 July 2020. The detailed search strategy was shown in Appendix 1. After removing the duplicates, a two-stage study selection process was conducted by two reviewers (ZKW and $\mathrm{XCW}$ ). At the first stage, the two reviewers independently reviewed the title and abstract to exclude articles irrelevant to the systematic review. We focused on studies reporting the number of laboratory-confirmed positive tests of human infection with at least one of the common $\mathrm{HCoVs}$, including HCoV-NL63, HCoV-229E, HCoV-HKU1, and HCoVOC43. Studies focused on SARS-CoV, MERS-CoV, SARSCoV-2, or other irrelevant topics were excluded. And only journal articles with available full text in English would be included at this stage (Fig. 1). Then, the two reviewers independently read full texts of articles included in the initial stage. Articles that met one of the following exclusion criteria were excluded (Fig. 1):

(1) Studies whose coronaviruses data were not extractable.
(2) Studies without reporting study sites or the period of HCoVs data (daily, weekly, monthly, or yearly).

(3) Studies without reporting diagnostic test methods or in which coronavirus were not laboratory-confirmed.

(4) Studies lack of age distribution of subjects.

(5) Studies reporting secondary data or a subset of data which were available in other included studies.

Two reviewers (ZKW and $\mathrm{XCW}$ ) extracted data from included literatures independently. General information of each study was collected, including study sites, coronaviruses species (NL63, 229E, HKU1, or OC43), laboratory or diagnostic test methods, age distribution of subjects, underlying comorbidity of subjects, period of data availability, number of positive tests, and number of total specimens. When two or more studies were available for the same type of coronavirus data from the same study site during the same period, we only extracted and included the one with the largest number of tested specimens. All differences of opinion regarding article selection and data extraction were resolved through discussion.

MERS data were collected from the World Health Organization (WHO)'s case reports from 2012 to 2020 (WHO 2021a, b) (Fig. 1). We extracted the sites (at least accurate to the country level) of these cases, and the relative date, including date of notification to the WHO, date of symptoms onset, date of hospitalization (because of MERS), date of laboratory confirmation, and date of outcome. Because of different ways of finding MERS cases and delays in reporting them, as well as the incomplete epidemiological investigation of the cases, we could not extract all the above five dates among majority of these cases. As an alternative, we used the earliest date of the above relative dates provided as cases' date of MERS onset. Each country's total population from 2012 to 2020 from the website of the United Nations for calculation of the incidence rate was also extracted (United Nations 2019).

SARS data of China at province level from 2003 to 2004 were collected from the China Ministry of Health (National Health Commission of the People's Republic of China 2003), while the case reports of SARS in other countries except China were collected from the website of the WHO (WHO 2015, 2021c)(Fig. 1). The SARS data in China were collected at province level because SARS cases were rarely reported in other countries; the province-level data could help us better understand the associations of SARS with environmental factors in different conditions considering the different climatic zones in China. For case reports that we could extract detailed case information, the date of SARS onset of the cases was chosen by a same process as MERS date mentioned before; while for the reports that only reported the case numbers at a specific period, the reporting date was used as the date of SARS onset of these cases. The total population of each 


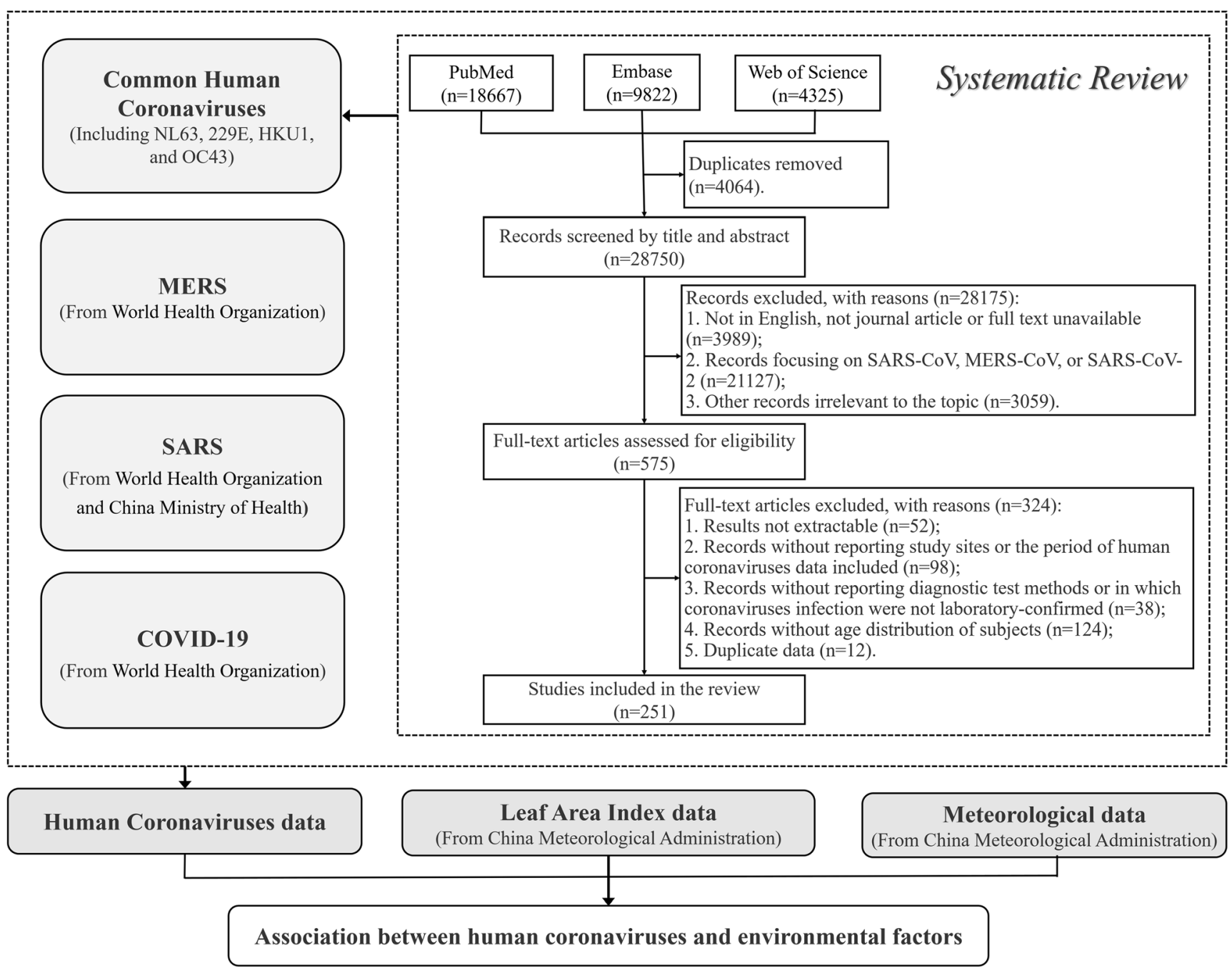

Fig. 1 Study profile flowchart

country from 2003 to 2004 was also extracted from United Nations (United Nations 2019), and the total population of each province in China was extracted from China Statistical Yearbook(National Bureau of Statistics of the People's Republic of China 2005).

COVID-19 data were daily numbers of new COVID-19 cases reported at country level from January 20, 2020, to December 31, 2020, which were extracted from the WHO's dataset (Hannah et al. 2020)(Fig. 1). Because the detailed case information, such as date of symptoms onset, was unavailable, we could only use the reporting date of each country as the date of COVID-19 onset of these cases. Each country's total population of 2020 was also extracted from the United Nations as mentioned before (United Nations 2019). Considering that the COVID-19's epidemic was closely relative to non-pharmaceutical interventions, behaviors change, and other policies, we also extracted the government response index from the Oxford COVID-19 Government Response Tracker (OxCGRT) for further adjustment. The overall government response index from OxCGRT is a comprehensive indicator (range from 0 to 100) that reflects the level of government action, which integrates 23 indicators from containment and closure, economic, health system, and vaccine policies (University of Oxford 2020).

Meteorological data were provided by the China Meteorological Administration (Fig. 1). The data covered nearly 9000 monitoring sites around the world, which included the following daily indicators: average temperature $\left({ }^{\circ} \mathrm{C}\right)$, maximum temperature $\left({ }^{\circ} \mathrm{C}\right)$, minimum temperature $\left({ }^{\circ} \mathrm{C}\right)$, dewpoint temperature $\left({ }^{\circ} \mathrm{C}\right)$, average wind speed $(\mathrm{m} / \mathrm{s})$, precipitation amount $(\mathrm{mm})$, and visibility $(\mathrm{km})$. In addition, we also calculated daily temperature range $\left({ }^{\circ} \mathrm{C}\right)$ and relative humidity (\%) based on the above data (Appendix 2).

Vegetation coverage data were leaf area index (LAI) data provided by the China Meteorological Administration, which referred to the multiple of the total plant leaf area per unit land area (Fig. 1). It is a complex index to indicate the density and structure of vegetation. The global LAI data was collected by Moderate Resolution Imaging Spectroradiometer based on satellite remote sensing technology and was provided as raster 
data with $500-\mathrm{m}(\mathrm{m})$ pixel size. Because the LAI was updated every 16 days, we assumed that the LAI was same during the date of one update to the next update. In addition, the LAI in 2020 has not been updated yet, therefore, we used the LAI data in 2019 to represent that in 2020 as an alternative.

\section{Measures of variables}

The following definitions and calculations of variables were used in this study:

(1) Positive rate of common HCoVs: We defined the common HCoVs' positive rate as the rate of positive tests in each study site during reported periods. And the positive rate was calculated as the formula below:

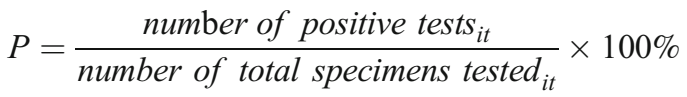

where $P$ was coronaviruses' positive rate, $i$ denoted the study site, and $t$ denoted the study period. We calculated overall positive rate for common $\mathrm{HCoVs}\left(P_{\text {Overall }}\right)$ and the positive rate for each species $\left(P_{\mathrm{NL} 63}, P_{229 \mathrm{E}}, P_{\mathrm{HKU} 1}, P_{\mathrm{OC} 43}\right)$. For the calculation of $P_{\text {Overall }}$, number of positive tests equals to the sum of positive specimens for any species of common HCoVs. For the calculation of $P_{\mathrm{NL} 63}, P_{229 \mathrm{E}}, P_{\mathrm{HKU} 1}$, or $P_{\mathrm{OC} 43}$, number of positive tests equals to the sum of positive specimens for each species. And the most detailed time scale of the positive rate was the monthly positive rate of the common $\mathrm{HCoVs}$.

(2) Incidence rate of MERS, SARS, and COVID-19: To increase the comparability of MERS, SARS, and COVID-19 data with common HCoVs' positive rate, the monthly incidence rate of MERS (I $I_{\text {MERS }}$ ), SARS $\left(I_{\text {SARS }}\right)$, and COVID-19 ( $\left.I_{\text {COVID-19 }}\right)$ of each country was calculated as the formula below:

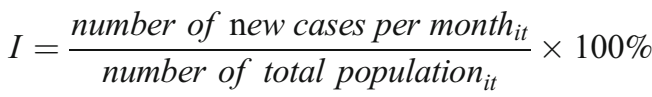

where $I$ was the incidence rate, $i$ denoted the study site (the country of MERS, SARS, or COVID-19 cases), and $t$ denoted the specific month. For MERS and SARS data, the number of new cases of one geographical unit (province or country) in a specific month was the sum of the MERS, SARS, or COVID19 cases of that geographical unit in the month based on each case's date of disease onset. And because it was difficult to obtain the monthly number of total populations, we used annual total population of each country as an alternative.
(3) The monthly average meteorological factors, LAI, and government response index (for COVID-19 only) in specific geographical areas were also calculated for further analyses.

\section{Method of inquiry and data analysis procedure}

The geographical coordinates were used as the linkage of virus data and environmental data. For common $\mathrm{HCoVs}$ data collected from the literatures, specific sites among included studies were located to city level at least and some to specific hospital or laboratory. We extracted the geographical coordinates for each study site using Microsoft Bing Maps (https:// cn.bing.com/maps). Based on the geographical coordinates of each study site, we extracted meteorological data in the study site's nearest monitoring stations and LAI data in the raster that the study site was in. Then, we linked the $\mathrm{HCoV}$ data and environmental data at the same study periods. In addition, the monthly average of government response index in each country was also linked with the COVID-19 data.

In the descriptive analyses, we calculated the median and interquartile range (IQR) for common $\mathrm{HCoVs}$ ' positive rate and monthly incidence rate of MERS, SARS, and COVID-19 because of non-normal distribution. For the normal distribution data including meteorological factors and LAI, we described with mean, standard deviation (SD), and range.

Generalized additive models (GAMs) with a QuasiPoisson regression and adjustment of time effect were used to estimate the effects of environmental factors on $P_{\text {Overall }}$, $P_{\mathrm{NL} 63}, P_{229 \mathrm{E}}, P_{\mathrm{HKU} 1}, P_{\mathrm{OC} 43}, I_{\mathrm{MERS}}, I_{\mathrm{SARS}}$, and $I_{\mathrm{COVID}-19}$. As for the establishing of multivariable GAMs, the multicollinearity of the environmental factors and the deviance explained (the higher the better) of models were taken into consideration together to select better models (Appendix 2). Finally, the average temperature, temperature range, average wind speed, relative humidity, precipitation, visibility, and LAI were included in the multivariable models. For COVID19 , government response index was adjusted in the multivariable GAM. To avoid overfitting, optimal estimated degrees of freedom (edf) and the number of knots on smoothing terms were selected according to the lowest generalized cross validation (GCV) score (the lower the better). We also calculated relative risks (RRs) and 95\% confidence intervals (CIs) to quantitatively estimate the association of environmental factors with positive rates of common $\mathrm{HCoVs}$ and incidence rate of MERS, SARS, and COVID-19. The similarity of two HCoVs' association with one environmental factor was identified if association in the same direction was observed within a similar range of that environmental factor.

Subgroup analysis was done to explore the similarities and differences in common HCoVs' association with the environmental factors among different age groups and underlying 
medical conditions. And to make the COVID-19 data more comparable, a sensitivity analysis was conducted that only countries provided common HCoVs' positive rates were included in the analysis of exploring environmental factors' association with COVID-19.

All data analyses were conducted in R software (version 4.0.3). GAMs were implemented using "mgcv" package (version 1.8-33), and RRs with their 95\%CIs were calculated using the "oddsratio" package (version 2.0.1). A two-sidedpvalue of less than 0.05 was considered statistically significant.

\section{Results}

A total of 251 studies, among which the earliest study was published in 1972, were included in the data extraction of common HCoVs (Fig. 1, Appendix 1). There were 263 study sites distributed in 63 countries of six continents around the world (Fig. 2, Appendix 3 Table S1). A total of 1,424,751 specimens were collected among these studies, with a median positive rate of $3.39 \%$ (1.11-6.67\%) (Fig. 3a, Table 1). MERS cases distributed in 27 countries with a median monthly incidence rate of 0.03 per million ( $0.03-0.39$ per million), and majority of MERS cases were in the Middle East area, especially in the Kingdom of Saudi Arabia and the United Arab Emirates (Fig. 3b). There were 27 countries that reported SARS cases from 2003 to 2004; the worldwide median monthly incidence rate of SARS was 0.07 per million (0.040.53 per million) (Fig. 3c). COVID-19 had a wider pandemic globally than SARS and MERS with a median monthly incidence rate of 12.72 per million ( $0.88-24.80$ per million) (Fig. $3 \mathrm{~d})$. For the environmental factors, because MERS cases were mainly in the Middle East area, the average temperature for MERS $\left(26.19 \pm 8.22^{\circ} \mathrm{C}\right)$ was relatively higher than other HCoVs; while the relative humidity $(35.82 \pm 20.98 \%)$ and LAI $(1.42 \pm 2.29)$ were relatively lower (Appendix 3 Table S2).

Average temperature was associated with all the seven coronaviruses. When the average temperature was above $5.0^{\circ} \mathrm{C}$, the similar significantly negative association with average temperature was found among $I_{\mathrm{COVID}-19}\left(R R_{5-27^{\circ} \mathrm{C}}\right.$ : $0.24,95 \%$ CI: $0.23-0.26, p<0.05), P_{\text {Overall }}\left(R R_{<13^{\circ} \mathrm{C}}: 0.51\right.$, 95\%CI: $0.50-0.51, p<0.05), P_{\mathrm{NL} 63}(R R: 0.36,95 \% \mathrm{CI}: 0.18-$ $0.70, p<0.05)$, and $P_{\mathrm{HKU} 1}(R R: 0.82,95 \% \mathrm{CI}: 0.75-0.91$, $p<0.05$ ) (Fig. 4, Tables 2 and 3, Appendix 3 Fig. S1). In addition, negative association was also found between average temperature and $P_{229 \mathrm{E}}$ when temperature was below $10.0^{\circ} \mathrm{C}(R R: 0.66,95 \% \mathrm{CI}: 0.54-0.82, p<0.05)$, but positive association when temperature was between 10 and $24^{\circ} \mathrm{C}$ (RR: $2.35,95 \%$ CI: $2.16-2.54, p<0.05$ ). When average temperature was below $14.0^{\circ} \mathrm{C}$, the increase of temperature could contribute to the decrease of $P_{\mathrm{OC} 43}(R R: 0.23,95 \% \mathrm{CI}: 0.17-$ $0.32, p<0.05$ ); however, the increase of temperature could contribute to the increase of $I_{\text {SARS }}$ on the contrary (RR: 2.94, 95\%CI: $1.07-8.05, p<0.05)$. For the association between average temperature and $I_{\text {MERS }}$, the increase of temperature could significantly contribute to the increase of $I_{\text {MERS }}$ when average temperature was below $27.0^{\circ} \mathrm{C}(R R: 1.94,95 \% \mathrm{CI}$ : 1.23-3.04, $p<0.05$ ) (Fig. 4, Tables 2 and 3, Appendix 3 Fig. S1).

Similar inversed U-shaped association with temperature range was found among $I_{\mathrm{MERS}}, P_{\text {Overall }}, P_{\mathrm{NL} 63}$, and $P_{229 \mathrm{E}}$, of which the association was not significant in $P_{\text {Overall }}$ and $P_{\mathrm{NL} 63}$ $(p>0.05)$. When the temperature range was under $11^{\circ} \mathrm{C}$, the $I_{\text {MERS }}(R R: 2.28,95 \% \mathrm{CI}: 1.45-3.59, p<0.05)$ and $P_{229 \mathrm{E}}(R R$ : $3.62,95 \%$ CI: $1.57-8.35, p<0.05)$ increased when the temperature increased. On the contrary, U-shaped association with

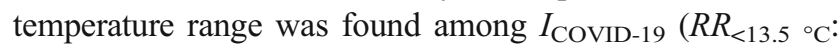
$0.51,95 \%$ CI: $0.40-0.65, p<0.05 ; R R_{\geq 13.5}{ }^{\circ} \mathrm{C}: 1.79,95 \%$ CI: $1.15-2.79, p<0.05)$ and $P_{\mathrm{HKU} 1}(p>0.05)$. And a linear positive association was found between temperature range and $P_{\mathrm{OC} 43}$, while significantly negative association was found in $I_{\text {SARS }}$. (Fig. 4, Tables 2 and 3, Appendix 3 Fig. S1).

$I_{\mathrm{SARS}}, P_{\text {Overall }}$, and $P_{\mathrm{NL} 63}$ had similar negative associations with relative humidity $(p<0.05)$. And the shape of exposure response curves among $P_{229 \mathrm{E}}, P_{\mathrm{HKU} 1}$, and $P_{\mathrm{OC} 43}$ were also similar, of which significant negative associations were observed in $P_{\mathrm{HKU}}$ when the relative humidity was between 66.0 and $80.0 \%$ (RR: $0.58,95 \% \mathrm{CI}: 0.47-0.02, p<0.05$ ) and in $P_{\mathrm{OC} 43}$ when the relative humidity was between 51.0 and $73.0 \%$ (RR: $0.39,95 \%$ CI: $0.26-0.59, p<0.05$ ), respectively. When the relative humidity was under $42.0 \%$, the increase of relative humidity could contribute to the increase of $I_{\text {MERS }}(R R: 1.46,95 \%$ CI: $1.38-1.55, p<0.05)$; however, when the relative humidity was above $42.0 \%$, the increase of relative humidity could contribute to the decrease of $I_{\text {MERS }}(R R$ : $0.27,95 \%$ CI: $0.09-0.79, p<0.05)$. In addition, $I_{\text {COVID-19 }}$ increased with the increase of relative humidity $(R R: 2.26$, 95\% CI: $1.56-3.28, p<0.05$ ) (Fig. 4, Tables 2 and 3, Appendix 3 Fig. S1).

With the increase of wind speed, $I_{\text {COVID-19 }}(R R: 0.73$, 95\%CI: $0.60-0.90, p<0.05)$ and $P_{\text {Overall }}(R R: 0.70,95 \%$ CI: $0.62-0.80, p<0.05)$ decreased gradually; on the contrary, $P_{229 \mathrm{E}}\left(R R_{2.0-5.0 \mathrm{~m} / \mathrm{s}}: 2.92,95 \% \mathrm{CI}: 2.71-3.15, p<0.05\right)$ and $P_{\mathrm{OC} 43}(R R: 2.09,95 \% \mathrm{CI}: 2.03-2.16, p<0.05)$ showed an increased trend. There was similarity in the shape of exposure response curves among $P_{\mathrm{NL63}}, I_{\mathrm{SARS}}$, and $I_{\mathrm{MERS}}$, of which significantly positive association was observed in $I_{\text {SARS }}$ when the wind speed was below $2.6 \mathrm{~m} / \mathrm{s}(R R: 17.88,95 \% \mathrm{CI}: 5.07-$ $63.06, p<0.05)$ and in $I_{\text {MERS }}$ when the wind speed was below $2.8 \mathrm{~m} / \mathrm{s}$ (RR: $3.49,95 \% \mathrm{CI}: 1.03-11.85, p<0.05$ ); and significantly negative association was observed in $P_{\mathrm{NL} 63}$ when the wind speed was between 2.0 and $4.0 \mathrm{~m} / \mathrm{s}(R R: 0.43,95 \% \mathrm{CI}$ : $0.40-0.45, p<0.05)$ and in $I_{\text {MERS }}$ when the wind speed was above $2.8 \mathrm{~m} / \mathrm{s}(R R: 0.01,95 \%$ CI: $0.00-0.04, p<0.05)$, respectively. In addition, with the increase of wind speed, the $P_{\mathrm{HKU}}$ 
Table 1 Common human coronaviruses' positive rate by characteristics

\begin{tabular}{|c|c|c|c|c|}
\hline & Total specimens $n(\%)$ & $\begin{array}{l}\text { Overall common HCoVs' positive } \\
\text { rate median (IQR) }(\%)\end{array}$ & Number of study sites & Number of studies \\
\hline Total & $1,424,751$ & $3.39(1.11 \sim 6.67)$ & 263 & 251 \\
\hline \multicolumn{5}{|l|}{ Age (years) } \\
\hline $0 \sim 18$ & $257,650(18.08)$ & $3.41(0.00 \sim 8.13)$ & 152 & 145 \\
\hline $19 \sim 64$ & $58,372(4.10)$ & $5.42(3.38 \sim 9.24)$ & 39 & 32 \\
\hline $65 \sim$ & $20,664(1.45)$ & $4.32(2.36 \sim 6.61)$ & 18 & 15 \\
\hline Others* & $1,088,065(76.37)$ & $3.43(1.47 \sim 6.00)$ & 145 & 129 \\
\hline \multicolumn{5}{|l|}{ Underlying medical conditions } \\
\hline Immune dysfunction & $1611(0.11)$ & $6.06(2.13 \sim 15.28)$ & 5 & 5 \\
\hline Cardiopulmonary anomaly & $5357(0.38)$ & $6.44(1.16 \sim 12.17)$ & 10 & 10 \\
\hline Organ transplant & $6547(0.46)$ & $2.35(2.04 \sim 3.87)$ & 5 & 5 \\
\hline Cancer & $583(0.04)$ & $2.88(1.66 \sim 6.19)$ & 3 & 3 \\
\hline Intestinal diseases & $783(0.05)$ & $7.73(5.73 \sim 10.98)$ & 3 & 3 \\
\hline General population & $1,409,870(98.96)$ & $3.35(1.90 \sim 7.33)$ & 236 & 179 \\
\hline
\end{tabular}

Note: $\mathrm{HCoV}$ human coronavirus

$I Q R$ interquartile range

*Others included studies that specific age groups could not be distinguished

significantly decreased when the wind speed was below $2.8 \mathrm{~m} /$ $\mathrm{s}(R R: 0.20,95 \% \mathrm{CI}: 0.12-0.33, p<0.05)$ and then increased when the wind speed was between 2.8 and $4.6 \mathrm{~m} / \mathrm{s}(R R: 3.12$, 95\%CI: 2.86-3.41, $p<0.05$ ) (Fig. 4, Tables 2 and 3, Appendix 3 Fig. S1).

Similar negative association with precipitation was found among $I_{\mathrm{COVID}-19}, I_{\mathrm{SARS}}, P_{229 \mathrm{E}}, P_{\mathrm{HKU} 1}$, and $P_{\mathrm{OC} 43}$ (Fig. 4 , Tables 2 and 3, Appendix 3 Fig. S1). On the contrary, $I_{\text {MERS }}$ (RR: 3.45, 95\% CI: $0.52-22.95, p>0.05), P_{\text {Overall }}\left(R R_{8.0-}\right.$ $33.0 \mathrm{~mm}: 4.22,95 \% \mathrm{CI}: 0.82-21.76, p>0.05)$, and $P_{\mathrm{NL} 63}(R R$ : 9.81, 95\%CI: $2.24-42.94, p<0.05)$ showed positive association with precipitation (Fig. 4, Tables 2 and 3, Appendix 3 Fig. S1).
Inversed U-shaped nonlinear association with visibility was observed among $I_{\mathrm{COVID}-19}, I_{\mathrm{SARS}}$, and $P_{\text {Overall }}$. Positive association was shown when visibility was below $14.0 \mathrm{~km}$ for $I_{\mathrm{COVID}-19}$, below $13.0 \mathrm{~km}$ for $I_{\mathrm{SARS}}$, and below $14.0 \mathrm{~km}$ for $P_{\text {Overall }}$, respectively. And negative association was shown when visibility was higher than the above cutoff point ( $R R_{\mathrm{COVID}-19(14.0-33.0 \mathrm{~km})}: 0.33,95 \% \mathrm{CI}: 0.26-0.41, p<0.05$; $R R_{\text {SARS }}: 0.14,95 \%$ CI: $0.02-0.86, p<0.05$; $R R_{\text {Overall }}: 0.31$, 95\%CI: $0.09-1.09, p>0.05$ ) (Fig. 4, Tables 2 and 3, Appendix 3 Fig. S1). Similar negative association with visibility was showed among $P_{\mathrm{NL} 63}, P_{229 \mathrm{E}}, P_{\mathrm{HKU} 1}$, and $P_{\mathrm{OC} 43}$. In addition, with the increase of visibility, $I_{\text {MERS }}$ decreased when the visibility was below $8.5 \mathrm{~km}(R R: 0.48,95 \% \mathrm{CI}: 0.42-0.54$,
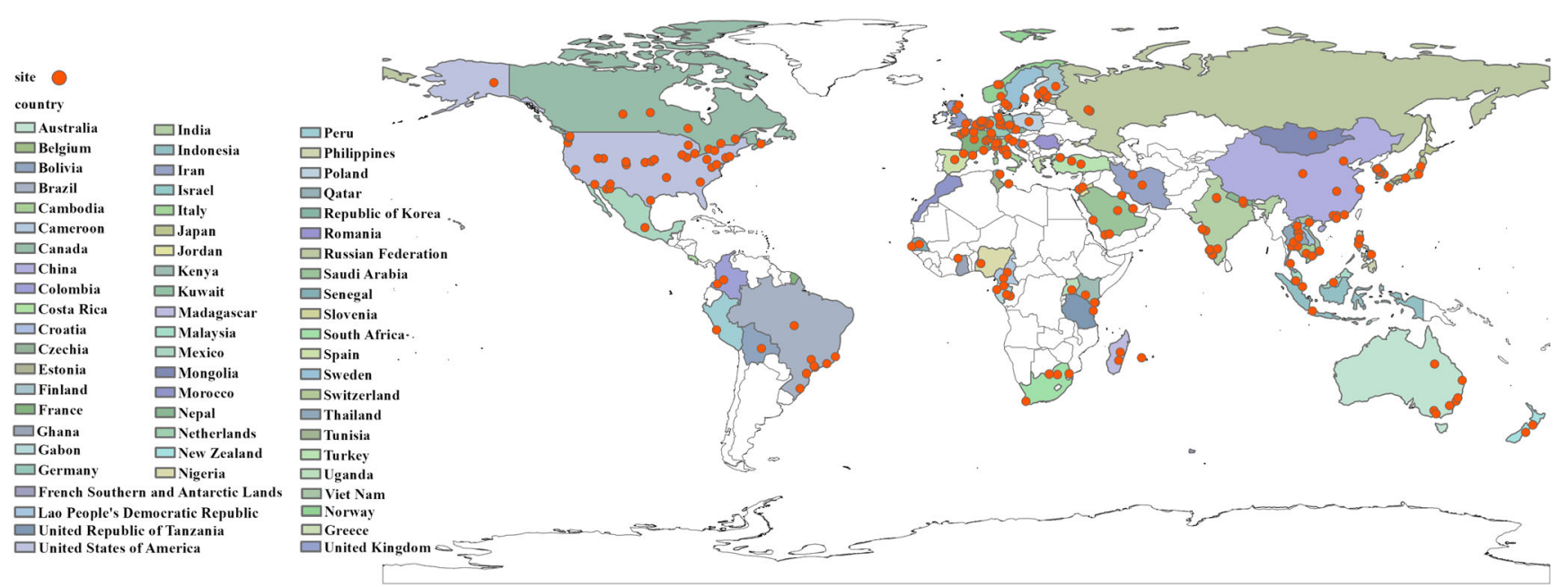

Fig. 2 Global distribution of common human coronaviruses' study sites 


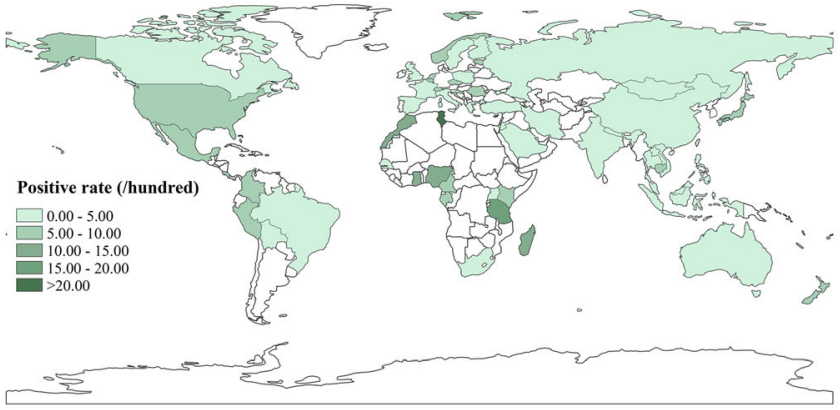

(a) common HCoVs positive rate (NL63, 229E, HKU1, and OC43)

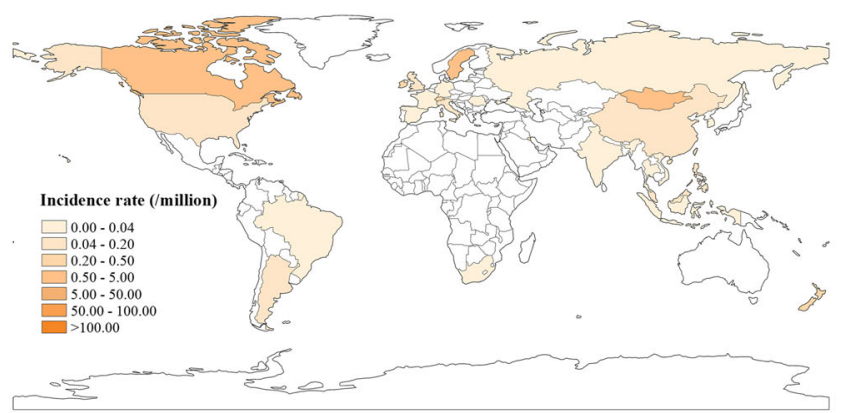

(c) SARS incidence rate

Fig. 3 Global epidemic of human coronaviruses. a Common HCoVs positive rate (NL63, 229E, HKU1, and OC43), b MERS incidence rate, c SARS incidence rate, dCOVID-19 incidence rate. (HCoV, human

$p<0.05)$, increased when the visibility was between 8.5 and $16.0 \mathrm{~km}(R R: 6.01,95 \% \mathrm{CI}: 4.09-8.82, p<0.05)$, and then decreased when the visibility was above $16.0 \mathrm{~km}(R R: 0.32$, 95\% CI: 0.12-0.83, $p<0.05$ ) (Fig. 4, Tables 2 and 3, Appendix 3 Fig. S1).

Similar significantly negative association with LAI was found among $I_{\text {COVID-19 }}\left(R R_{<35.0}\right.$ : 0.66, 95\%CI: 0.68-0.69, $p<0.05), P_{\text {Overall }}(R R: 0.37,95 \% \mathrm{CI}: 0.18-0.78, p<0.05)$, $P_{\mathrm{NL} 63}(R R: 0.18,95 \%$ CI: $0.07-0.48, p<0.05), P_{229 \mathrm{E}}(R R$ : $0.30,95 \% \mathrm{CI}: 0.17-0.54, p<0.05)$, and $P_{\mathrm{HKU} 1}(R R: 0.47$, 95\%CI: $0.24-0.90, p<0.05$ ) (Fig. 4, Tables 2 and 3, Appendix 3 Fig. S1). For the association between LAI and $P_{\mathrm{OC} 43}$, the increase of LAI could contribute to the increase of $P_{\mathrm{OC} 43}$ when the LAI was below 23.0 ( $R R: 2.40,95 \% \mathrm{CI}: 2.39$ $2.42, p<0.05)$; however, when the LAI was above 23.0, the increase of LAI could contribute to the decrease of $P_{\mathrm{OC} 43}(R R$ : $0.24,95 \%$ CI: $0.09-0.67, p<0.05)$. And with the increase of LAI, $I_{\text {SARS }}$ increased when the LAI was below 10.5 , decreased when the LAI was between 10.5 and 20.0, and then increased when the LAI was above $20.0(p<0.05)$ (Fig. 4, Tables 2 and 3, Appendix 3 Fig. S1).

The sensitivity analysis of COVID-19's incidence also showed similar results with the main analysis in the association with average temperature, wind speed, precipitation, visibility, and LAI (Appendix 3 Fig. S2, Table S3). And the negative association in the sensitivity analysis was partly similar to the main analysis of COVID-19 data when the temperature range

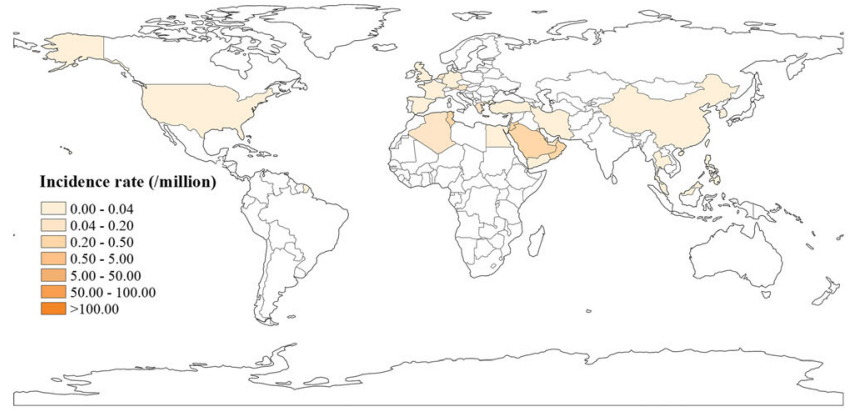

(b) MERS incidence rate

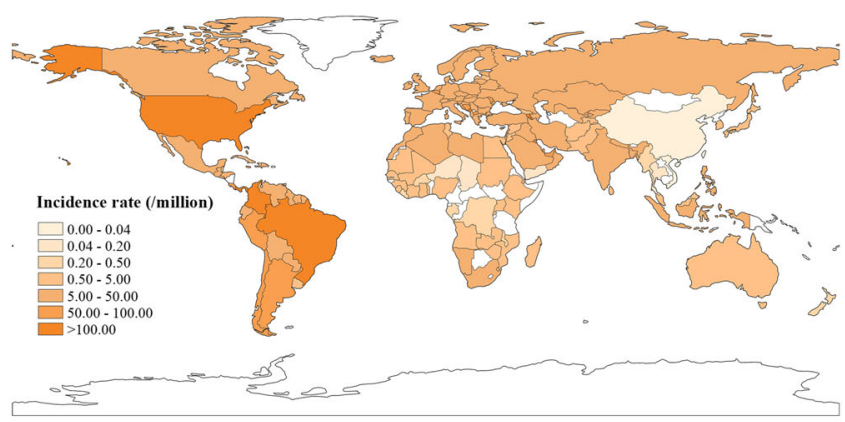

(d) COVID-19 incidence rate

coronavirus, while the NL63, 229E, HKU1, and OC43 were the four kinds of HCoVs. MERS, Middle East respiratory syndrome. SARS, severe acute respiratory syndrome. COVID-19, coronavirus disease 2019)

was below $13.5^{\circ} \mathrm{C}(R R: 0.10,95 \% \mathrm{CI}: 0.09-0.10, p<0.05)$, while the sensitivity analysis showed a U-shaped association between relative humidity and $I_{\mathrm{COVID}-19}$; however, the association was not significant $(p>0.05)$ (Appendix 3 Fig. S2, Table S3).

In the subgroup analysis of common HCoVs' positive rate with environmental factors, heterogeneity was shown among different age groups in the associations of HCoVs' positive rate with average temperature, temperature range, relative humidity, visibility, and LAI. However, similar negative associations and similar positive associations were observed among the three age groups in the associations of the positive rate with wind speed and precipitation, respectively (Appendix 3). In addition, the similar significantly negative association of common HCoVs' positive rate with average temperature and relative humidity were observed in people with underlying diseases and general population $(p<0.05)$. However, the significant associations were opposite in some parts of the value range of precipitation, visibility, and LAI among people with underlying diseases or not $(p<0.05)$ (Appendix 3 Fig. S3, Table S4).

\section{Discussion}

In this study, we have demonstrated that there are wide associations between $\mathrm{HCoVs}$ and environmental factors on a global scale. And to our knowledge, this study is the first to 


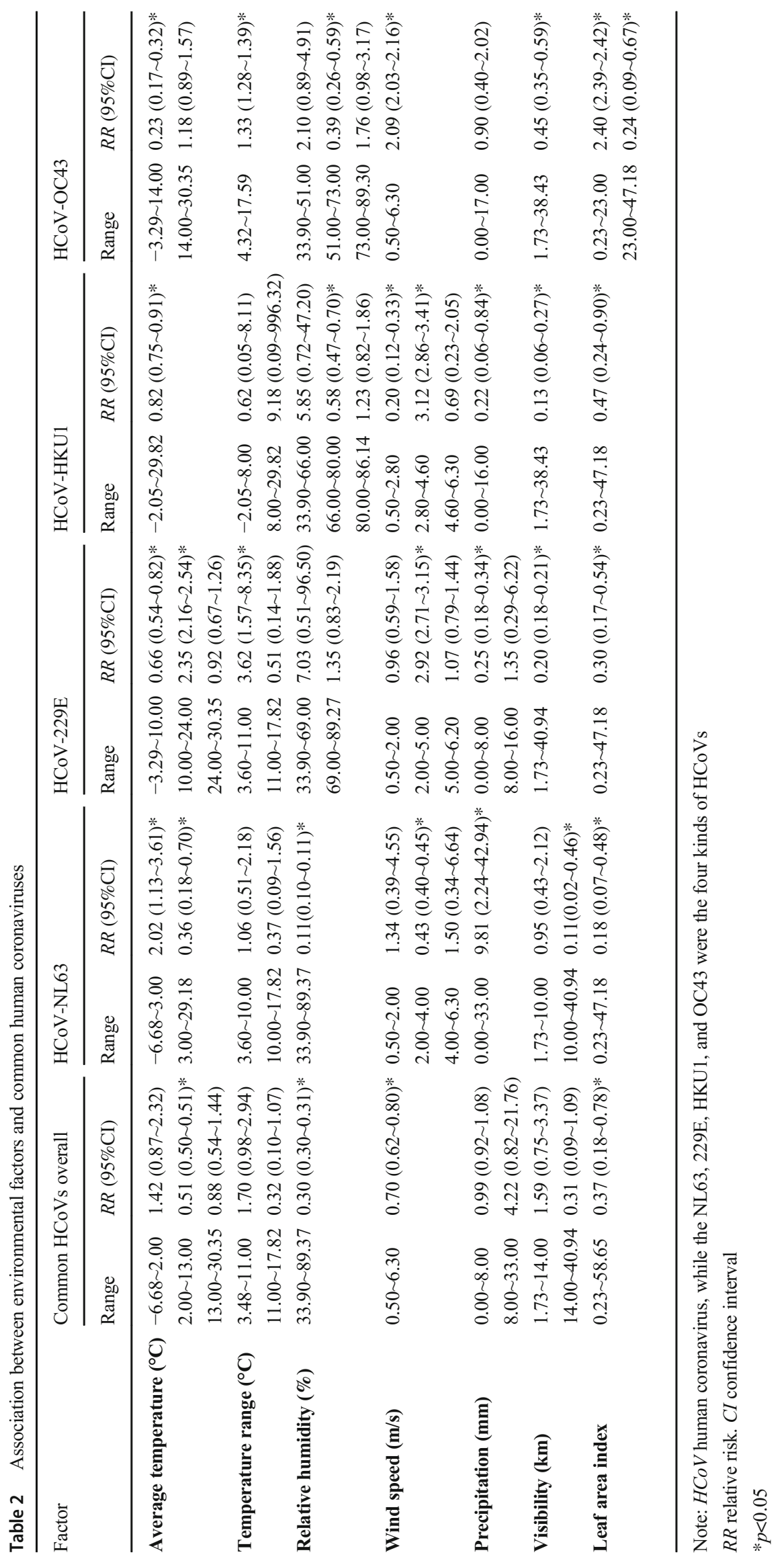


Table 3 Association of environmental factors with MERS, SARS, and COVID-19

\begin{tabular}{|c|c|c|c|c|c|c|}
\hline \multirow[t]{2}{*}{ Factor } & \multicolumn{2}{|l|}{ MERS } & \multicolumn{2}{|l|}{ SARS } & \multicolumn{2}{|l|}{ COVID-19 \# } \\
\hline & Range & $R R(95 \% \mathrm{CI})$ & Range & $R R(95 \% \mathrm{CI})$ & Range & $R R(95 \% \mathrm{CI})$ \\
\hline \multirow[t]{3}{*}{ Average temperature $\left({ }^{\circ} \mathrm{C}\right)$} & $8.56 \sim 27.00$ & $1.94(1.23 \sim 3.04)^{*}$ & $-3.07 \sim 14.00$ & $2.94(1.07 \sim 8.05)^{*}$ & $-20.43 \sim 5.00$ & $7.60(2.58 \sim 22.42)^{*}$ \\
\hline & $27.00 \sim 39.17$ & $0.87(0.60 \sim 1.25)$ & $14.00 \sim 31.40$ & $0.18(0.13 \sim 0.26)^{*}$ & $5.00 \sim 27.00$ & $0.24(0.23 \sim 0.26)^{*}$ \\
\hline & & & & & $27.00 \sim 38.89$ & $1.09(0.64 \sim 1.86)$ \\
\hline \multirow[t]{3}{*}{ Temperature range $\left({ }^{\circ} \mathrm{C}\right)$} & $5.72 \sim 13.50$ & $2.28(1.45 \sim 3.59)^{*}$ & $3.39 \sim 10.00$ & $0.06(0.02 \sim 0.17)^{*}$ & $2.74 \sim 13.50$ & $0.51(0.40 \sim 0.65)^{*}$ \\
\hline & $13.50 \sim 18.61$ & $0.89(0.59 \sim 1.32)$ & $10.00 \sim 12.00$ & $1.06(0.99 \sim 1.12)$ & $13.50 \sim 19.03$ & $1.79(1.15 \sim 2.79) *$ \\
\hline & & & $12.00 \sim 20.36$ & $0.00(0.00 \sim 0.04) *$ & & \\
\hline \multirow[t]{2}{*}{ Relative humidity (\%) } & $8.38 \sim 42.00$ & $1.46(1.38 \sim 1.55)^{*}$ & $22.27 \sim 94.11$ & $0.01(0.00 \sim 0.02)^{*}$ & $10.39 \sim 93.27$ & $2.26(1.56 \sim 3.28)^{*}$ \\
\hline & $42.00 \sim 90.92$ & $0.27(0.09 \sim 0.79)^{*}$ & & & & \\
\hline \multirow[t]{2}{*}{ Wind speed $(\mathbf{m} / \mathbf{s})$} & $0.10 \sim 2.80$ & $3.49(1.03 \sim 11.85)^{*}$ & $0.80 \sim 2.60$ & $17.88(5.07 \sim 63.06)^{*}$ & $0.40 \sim 9.30$ & $0.73(0.60 \sim 0.90) *$ \\
\hline & $2.80 \sim 6.60$ & $0.01(0.00 \sim 0.04)^{*}$ & $2.60 \sim 7.40$ & $0.01(0.00 \sim 138.62)$ & & \\
\hline Precipitation (mm) & $0.00 \sim 16.00$ & $3.45(0.52 \sim 22.95)$ & $0.00 \sim 13.00$ & $0.00(0.00 \sim 0.01)^{*}$ & $0.00 \sim 42.00$ & $0.30(0.12 \sim 0.76)^{*}$ \\
\hline \multirow[t]{3}{*}{ Visibility (km) } & $4.28 \sim 8.50$ & $0.48(0.42 \sim 0.54) *$ & $0.00 \sim 13.00$ & $9.49(2.92 \sim 30.81)^{*}$ & $3.59 \sim 14.00$ & $1.71(1.51 \sim 1.94)^{*}$ \\
\hline & $8.50 \sim 16.00$ & $6.01(4.09 \sim 8.82) *$ & $13.00 \sim 29.15$ & $0.14(0.02 \sim 0.86)^{*}$ & $14.00 \sim 33.00$ & $0.33(0.26 \sim 0.41)^{*}$ \\
\hline & $16.00 \sim 19.79$ & $0.32(0.12 \sim 0.83)^{*}$ & & & $33.00 \sim 43.71$ & $1.09(0.51 \sim 2.31)$ \\
\hline \multirow[t]{3}{*}{ Leaf area index } & $0.34 \sim 15.38$ & $0.45(0.07 \sim 3.03)$ & $0.80 \sim 10.50$ & $23.26(17.67 \sim 30.62)^{*}$ & $0.43 \sim 35.00$ & $0.69(0.68 \sim 0.69) *$ \\
\hline & & & $10.50 \sim 20.00$ & $0.10(0.04 \sim 0.25)^{*}$ & $35.00 \sim 63.68$ & $1.10(0.85 \sim 1.44)$ \\
\hline & & & $20.00 \sim 29.63$ & $89.23(62.53 \sim 127.33)^{*}$ & & \\
\hline
\end{tabular}

Note: MERS Middle East respiratory syndrome. SARS severe acute respiratory syndrome

COVID-19 coronavirus disease 2019

$R R$ relative risk. $C I$ confidence interval

\# The government response index from the Oxford COVID-19 Government Response Tracker (OxCGRT) was adjusted in the model $* p<0.05$

\begin{tabular}{|c|c|c|c|c|c|c|c|c|}
\hline Environmental factors & $\begin{array}{c}\text { common } \mathrm{HCoVs} \\
\text { Overall }\end{array}$ & HCoV-NL63 & HCoV-229E & HCoV-HKU1 & HCoV-OC43 & MERS & SARS & COVID-19 \\
\hline Average temperature & $\begin{array}{l}\mathrm{P}\left(-6.68 \sim 2.00^{\circ} \mathrm{C}\right)- \\
\mathrm{N}\left(2.00 \sim 13.00^{\circ} \mathrm{C}\right)- \\
\mathrm{N}\left(13.00 \sim 30.35^{\circ} \mathrm{C}\right)\end{array}$ & $\begin{array}{l}\mathrm{P}\left(-6.68 \sim 3.00^{\circ} \mathrm{C}\right)- \\
\mathrm{N}\left(3.00 \sim 29.18^{\circ} \mathrm{C}\right)\end{array}$ & $\begin{array}{l}\text { N(-3.29 10.00 } \\
\text { P }\left(10.00 \sim 24.00^{\circ} \mathrm{C}\right)- \\
\text { N }\left(24.00 \sim 30.35^{\circ} \mathrm{C}\right)\end{array}$ & $\mathrm{N}\left(-2.05 \sim 29.82^{\circ} \mathrm{C}\right)$ & $\begin{array}{l}\mathrm{N}\left(-3.29 \sim 14.00^{\circ} \mathrm{C}\right)- \\
\mathrm{P}\left(14.00 \sim 30.35^{\circ} \mathrm{C}\right)\end{array}$ & $\begin{array}{l}\mathrm{P}\left(8.56 \sim 27.00^{\circ} \mathrm{C}\right)- \\
\mathrm{N}\left(27.00 \sim 39.17^{\circ} \mathrm{C}\right)\end{array}$ & $\begin{array}{l}\mathrm{P}\left(-3.07 \sim 14.00^{\circ} \mathrm{C}\right)- \\
\mathrm{N}\left(14.00 \sim 31.40^{\circ} \mathrm{C}\right)\end{array}$ & $\begin{array}{l}\mathbf{P}\left(-20.43 \sim 5.00^{\circ} \mathrm{C}\right)- \\
\mathbf{N}\left(5.00 \sim 27.00^{\circ} \mathrm{C}\right)- \\
\mathbf{P}\left(27.00 \sim 38.89^{\circ} \mathrm{C}\right)\end{array}$ \\
\hline Temperature range & $\begin{array}{l}\mathrm{P}\left(3.48 \sim 11.00^{\circ} \mathrm{C}\right)- \\
\mathrm{N}\left(11.00 \sim 17.82^{\circ} \mathrm{C}\right)\end{array}$ & $\begin{array}{l}\mathrm{P}\left(3.60 \sim 10.00^{\circ} \mathrm{C}\right)- \\
\mathrm{N}\left(10.00 \sim 17.82^{\circ} \mathrm{C}\right)\end{array}$ & $\begin{array}{l}\mathrm{P}\left(3.60 \sim 11.00^{\circ} \mathrm{C}\right)- \\
\mathrm{N}\left(11.00 \sim 17.82^{\circ} \mathrm{C}\right)\end{array}$ & $\begin{array}{l}\mathrm{N}\left(-2.05 \sim 8.00^{\circ} \mathrm{C}\right)- \\
\mathrm{P}\left(8.00 \sim 29.82^{\circ} \mathrm{C}\right)\end{array}$ & $\mathrm{P}\left(4.32 \sim 17.59^{\circ} \mathrm{C}\right)$ & $\begin{array}{l}\mathrm{P}\left(5.72 \sim 13.50^{\circ} \mathrm{C}\right)- \\
\mathrm{N}\left(13.50 \sim 18.61^{\circ} \mathrm{C}\right)\end{array}$ & $\begin{array}{l}\mathrm{N}\left(3.39 \sim 10.00^{\circ} \mathrm{C}\right)- \\
\mathrm{P}\left(10.00 \sim 12.00^{\circ} \mathrm{C}\right)- \\
\mathrm{N}\left(12.00 \sim 20.36^{\circ} \mathrm{C}\right)\end{array}$ & $\begin{array}{l}\mathrm{N}\left(2.74 \sim 13.50^{\circ} \mathrm{C}\right)- \\
\mathrm{P}\left(13.50 \sim 19.03^{\circ} \mathrm{C}\right)\end{array}$ \\
\hline Relative humidity & $\mathrm{N}(33.90 \sim 89.37 \%)$ & $\mathrm{N}(33.90 \sim 89.37 \%)$ & $\begin{array}{l}\mathrm{P}(33.90 \sim 69.00 \%)- \\
\mathrm{P}(69.00 \sim 89.27 \%)\end{array}$ & $\begin{array}{l}\text { P(33.90 66.00\%)- } \\
\text { N(66.00 80.00\%)- } \\
\text { P(80.00 86.14\%) }\end{array}$ & $\begin{array}{l}\text { P(33.90 51.00\%)- } \\
\text { N(51.00 73.00\%)- } \\
\text { P(73.00 89.30\%) }\end{array}$ & $\begin{array}{l}\mathrm{P}(8.38 \sim 42.00 \%)- \\
\mathrm{N}(42.00 \sim 90.92 \%)\end{array}$ & $\mathrm{N}(22.27 \sim 94.11 \%)$ & $P(10.39 \sim 93.27 \%)$ \\
\hline Wind speed & $\mathrm{N}(0.50 \sim 6.30 \mathrm{~m} / \mathrm{s})$ & $\begin{array}{l}\mathrm{P}(0.50 \sim 2.00 \mathrm{~m} / \mathrm{s})- \\
\mathrm{N}(2.00 \sim 4.00 \mathrm{~m} / \mathrm{s})- \\
\mathrm{P}(4.00 \sim 6.30 \mathrm{~m} / \mathrm{s})\end{array}$ & $\begin{array}{l}\mathrm{N}(0.50 \sim 2.00 \mathrm{~m} / \mathrm{s})- \\
\mathrm{P}(2.00 \sim 5.00 \mathrm{~m} / \mathrm{s})- \\
\mathrm{P}(5.00 \sim 6.20 \mathrm{~m} / \mathrm{s})\end{array}$ & $\begin{array}{l}\mathrm{N}(0.50 \sim 2.80 \mathrm{~m} / \mathrm{s})- \\
\mathrm{P}(2.80 \sim 4.60 \mathrm{~m} / \mathrm{s})- \\
\mathrm{N}(4.60 \sim 6.30 \mathrm{~m} / \mathrm{s})\end{array}$ & $\mathrm{P}(0.50 \sim 6.30 \mathrm{~m} / \mathrm{s})$ & $\begin{array}{l}\mathrm{P}(0.10 \sim 2.80 \mathrm{~m} / \mathrm{s})- \\
\mathrm{N}(2.80 \sim 6.60 \mathrm{~m} / \mathrm{s})\end{array}$ & $\begin{array}{l}\mathrm{P}(0.80 \sim 2.60 \mathrm{~m} / \mathrm{s})- \\
\mathrm{N}(2.60 \sim 7.40 \mathrm{~m} / \mathrm{s})\end{array}$ & $\mathrm{N}(0.40 \sim 9.30 \mathrm{~m} / \mathrm{s})$ \\
\hline Precipitation & $\begin{array}{l}\mathrm{N}(0.00 \sim 8.00 \mathrm{~mm})- \\
P(8.00-33.00 \mathrm{~mm})\end{array}$ & $\mathrm{P}(0.00 \sim 33.00 \mathrm{~mm})$ & $\begin{array}{l}\mathrm{N}(0.00 \sim 8.00 \mathrm{~mm})- \\
\mathrm{P}(8.00 \sim 16.00 \mathrm{~mm})\end{array}$ & $\mathrm{N}(0.00 \sim 16.00 \mathrm{~mm})$ & $\mathrm{N}(0.00 \sim 17.00 \mathrm{~mm})$ & $P(0.00 \sim 16.00 \mathrm{~mm})$ & $\mathrm{N}(0.00 \sim 13.00 \mathrm{~mm})$ & $\mathrm{N}(0.00 \sim 42.00 \mathrm{~mm})$ \\
\hline Visibility & $\begin{array}{l}P(1.73 \sim 14.00 \mathrm{~km})- \\
\mathrm{N}(14.00 \sim 40.94 \mathrm{~km})\end{array}$ & $\begin{array}{l}\mathrm{N}(1.73 \sim 10.00 \mathrm{~km})- \\
\mathrm{N}(10.00 \sim 40.94 \mathrm{~km})\end{array}$ & $\mathrm{N}(1.73-40.94 \mathrm{~km})$ & $\mathrm{N}(1.73 \sim 38.43 \mathrm{~km})$ & $\mathrm{N}(1.73 \sim 38.43 \mathrm{~km})$ & $\begin{array}{l}\mathrm{N}(4.28 \sim 8.50 \mathrm{~km})- \\
P(8.50 \sim 16.00 \mathrm{~km})- \\
\mathrm{N}(16.00 \sim 19.79 \mathrm{~km})\end{array}$ & $\begin{array}{l}\mathrm{P}(0.00 \sim 13.00 \mathrm{~km})- \\
\mathrm{N}(13.00 \sim 29.15 \mathrm{~km})\end{array}$ & $\begin{array}{l}P(3.59 \sim 14.00 \mathrm{~km})- \\
\mathbf{N}(14.00 \sim 33.00 \mathrm{~km}) \\
\mathbf{P}(33.00 \sim 43.71 \mathrm{~km})\end{array}$ \\
\hline Leaf area index & $\mathrm{N}(0.23 \sim 58.65)$ & $\mathrm{N}(0.23 \sim 47.18)$ & $\mathrm{N}(0.23 \sim 47.18)$ & $N(0.23 \sim 47.18)$ & $\begin{array}{l}P(0.23 \sim 23.00)- \\
N(23.00 \sim 47.18)\end{array}$ & $\mathrm{N}(0.34 \sim 15.38)$ & $\begin{array}{l}\mathrm{P}(0.80 \sim 10.50)- \\
\mathrm{N}(10.50 \sim 20.00)- \\
\mathrm{P}(20.00 \sim 29.63)\end{array}$ & $\begin{array}{l}\mathrm{N}(0.43 \sim 35.00)- \\
\mathbf{P}(35.00 \sim 63.68)\end{array}$ \\
\hline
\end{tabular}

$P$ : positive association between environmental factors and human coronaviruses' positive rate or incidence rate.

$\mathrm{N}$ : negative association between environmental factors and human coronaviruses' positive rate or incidence rate.

The effect of environmental factors on other human coronaviruses is similar with environmental factors' effect on COVID-19.

The effect of environmental factors on other human coronaviruses (except COVID-19) is similar with environmental factors' effect on SARS or MERS.

The effect of environmental factors on common human coronaviruses is similar with each other.

The effect of environmental factors on certain human coronavirus is different with the effect on other human coronaviruses.

Fig. 4 Comparison of association between environmental factors and human coronaviruses. (HCoV, human coronavirus, while the NL63, 229E, HKU1, and OC43 were the four kinds of HCoVs. MERS,
Middle East respiratory syndrome. SARS, severe acute respiratory syndrome. COVID-19, coronavirus disease 2019) 
compare the association between the seven HCoVs' epidemic and environmental factors. For the temperature, an inversed U-shaped association with daily average temperature was observed in the common HCoVs, MERS-CoV, SARS-CoV, and SARS-CoV-2, which was partly consistent with the negative association reported in most of the previous studies when the environmental temperature was above zero (du Prel et al. 2009; Notari 2021; Poirier et al. 2020). Laboratory studies have proved that temperature can influence the viral stability, viability, and activity, and viruses tend to survive longer in relative lower temperature, which could support the negative association (Pica and Bouvier 2012; Xu et al. 2021). Our finding also indicated that the sub-zero environmental temperature in the cold winter might also cause the inhibition of virus activity and slow down the epidemic, which needs further exploration. Humidity is also an important factor that influences the survival and spread of the virus. In the environment with lower relative humidity, especially combined with lower temperature, the viruses survived better and had higher virion stability because the salts in the aerosol crystallize more easily and droplets stay suspended longer in the air (Yang et al. 2012). In addition, the hosts' nasal epithelium inhibits mucociliary clearance and viral phagocytosis when the air is drying, which increases the susceptibility of the hosts (Eccles 2002; Salah et al. 1988; Casanova et al. 2010). Therefore, consisted with previous studies (Qi et al. 2020; Poirier et al. 2020; Ma et al. 2020), humidity was negatively associated with HCoV-NL63 (RR: $0.11,95 \%$ CI: $0.10-0.11)$ and SARS-CoV (RR: 0.01, 95\%CI: 0.00-0.02). However, another finding of previous study is that higher humidity $(80 \%)$ had a protective effect on HCoVs' survival (Casanova et al. 2010). And in our study, similar trend that humidity of over $80 \%$ contributed to the increasing positive rate of $\mathrm{HCoV}-229 \mathrm{E}$, HCoV-HKU1, HCoV-OC43, and COVID-19's incidence.

The relatively higher wind speed showed a positive effect on decreasing the incidence rate of COVID-19 (RR: 0.73, 95\%CI: $0.60-0.90$ ), which was consisted with previous evidence, and the reason was that higher wind speed could cause the shorter suspending time of SARS-CoV-2 in the air due to better dilution and removal effect of wind (Ma et al. 2020). However, the inversed U-shaped associations between wind speed and incidence rates of MERS and SARS were partly consistent with previous studies that Altamimi and Ahmed (2020) and Cai et al. (2007) reported the only negative associations of wind speed with MERS and SARS, respectively. While for the precipitation, the negative association with precipitation was found on COVID-19 (RR: 0.30, 95\%CI: 0.12$0.76, \mathrm{p}<0.05)$, which was consistent with previous study (Altamimi and Ahmed 2020). Overall, our findings in these associations could be supported by evidence from previous studies; however, there remain some differences. The differences of the findings between previous studies and our study might come from three aspects. Firstly, many studies were regional in a particular city or country (Anastasiou et al. 2021; du Prel et al. 2009; Tan et al. 2005; Gardner et al. 2019; Altamimi and Ahmed 2020; Ma et al. 2020), while our study focused on the global scale, which made the evidences we provided more comprehensive. Secondly, many studies were conducted at the beginning of the disease's epidemic, especially for COVID-19(Wu et al. 2020), which narrowed the variability of environmental factors. At last, the differences might also be caused by the different types of outcome and the different methods used to explore the associations among studies; for example, some studies used the number of cases as the outcome (Wu et al. 2020), and the statistical methods they used could not provide piecewise associations, such as linear regression (Pan et al. 2021).

Comparing with previous related studies, we creatively explored visibility and vegetation coverage's associations with the seven HCoVs. And similarly, negative associations were observed in the whole or at least a significant part of the exposure response curve between the two environmental factors and the seven $\mathrm{HCoVs}$. It has been proven the drop in the concentration of air pollutants (i.e., $\mathrm{PM}_{10}, \mathrm{PM}_{2.5}, \mathrm{NO}_{2}$, etc.) will improve visibility (You and Pan 2020; Chen and Xie 2013). The negative association between visibility and HCoVs showed the improvement of air quality could decrease the transmission of HCoVs. The possible reasons were as follows. Firstly, the reduction of particulate matter in the air reduces the attachment and duration of the virus in the air (Frontera et al. 2020). Secondly, higher visibility could improve the penetration of sunlight through the air; ultraviolet rays from sunlight are proven to have the ability to kill viruses in the air and environmental conditions, which were proved by Cherrie et al. (2013). In addition, better air quality has positive effects on human's immunity, which could reduce susceptibility to some extent (Horne et al. 2018; Xie et al. 2019; Xu et al. 2016). For the vegetation coverage, our finding was consisted with You et al.'s study (You and Pan 2020), which showed urban vegetation slows down the spread of COVID-19 in the USA. Indeed, areas with high vegetation coverage, such as the forests, might cluster many animal hosts of coronavirus. However, the human-to-human transmission was the main transmission route of $\mathrm{HCoVs}$ during the epidemic periods; the role of animals during the pandemic period of $\mathrm{HCoVs}$ was less important for most of the HCoVs. As one of the indexes to evaluate urban construction and quality of life in urban, vegetation in urban landscapes is critically important because it benefits city dwellers and the environment for its improvement in ecosystem functions to strengthen resistance to natural disasters caused by extreme weathers and improve the air quality (Kim 2016; Zitkovic 2008; Seitz and Escobedo 2014). Urban green spaces as a kind of public service, which could help city dwellers reduce stress, relax, and improve mental health, then improve health and quality of life (van Den Berg and Custers 2011; Ulrich 1984; Cecily Jane 
2009). Therefore, relatively higher urban vegetation coverage could help city and city dwellers improve resistance to the emerging infectious diseases.

Another novelty of this study is that after analyzing the environmental factors' association with these kinds of HCoVs separately, we could clearly compare the similarities and differences of the associations among these HCoVs. Recently, the pandemic of COVID-19 is ongoing. And the incidence rate of COVID-19 was more similar with that of more than three other HCoVs in the association's direction with daily average temperature, precipitation, and vegetation coverage (Fig. 4). And the most similarities were shown in COVID-19 and common HCoVs in the associations' direction with environmental factors, especially for HCoV-HKU1, which is also a kind of beta-CoV, in four factors including average temperature, temperature range, precipitation, and vegetation coverage (Fig. 4). This finding indicated that it is critically important to strengthen the surveillance of common HCoVs' epidemic and explore the global epidemic regularity of common $\mathrm{HCoVs}$ in depth, which could provide useful suggestions for prevention and control of COVID-19. Among the three $\mathrm{HCoVs}$ that caused highly pathogenic respiratory infections, few similarities were found between COVID-19 and MERS in their associations with environmental factors. The reason might be that majority of the MERS cases were from the Middle East area, which has unique environmental characteristics, such as higher temperature, lower relative humidity, and LAI; however, the values of these environmental factors included in the analysis of COVID-19 were more evenly integrated across the globe.

However, there were some limitations of this study. Firstly, there were differences in the positive rates of common $\mathrm{HCoVs}$ and the incidence rates of MERS, SARS, and COVID-19, which might cause bias in the comparison of environmental factors' effects on different HCoVs. However, country-level surveillance data for the common coronavirus is not available for most countries; data from literature sources are the best reflection of the epidemic of common HCoVs on a global scale under current conditions. Secondly, some control measures for common $\mathrm{HCoVs}$ were not included in the analysis, because no particular world-level or country-level control measures was conducted for common $\mathrm{HCoVs}$, which mainly caused the common cold. In the further studies, it is in need to strengthen country-level and worldwide surveillance of common $\mathrm{HCoVs}$, in order to better understand the characteristics of common HCoVs' epidemic around the world and provide more solid data. And more variables of air quality and air pollution can be considered in the modeling process in future studies. In addition, this study provides a perspective for researchers that monitoring of environmental factors is particularly important for the surveillance and early warning of infectious diseases' epidemic, and the epidemic regularity of viruses in the same family has a strong reference value for the prevention and control of emerging viruses.

\section{Conclusion}

In this study, we systematically explore and compare the associations between seven HCoVs' epidemic and environmental factors globally. Wide associations were found between $\mathrm{HCoVs}$ ' epidemic and environmental factors on a global scale; some of the associations were nonlinear. And COVID-19 has the most similarities in associations' direction with common HCoVs, especially for HCoV-HKU1 in four environmental factors including average temperature, temperature range, precipitation, and vegetation coverage. These findings indicated that it is in need to strengthen the important role of environmental factors in infectious disease surveillance, and the focus of environmental factors should go beyond meteorological factors and need to be expanded to include more vegetation coverage, air quality, and other factors. And the similarities between COVID-19 and common HCoVs in the association of environmental factors indicated that it is critically important to strengthen surveillance on common $\mathrm{HCoVs}$ in further research and management for better prevention and control of severe human coronavirus diseases.

Abbreviations $H C o V s$, human coronaviruses; MERS, Middle East respiratory syndrome; SARS, severe acute respiratory syndrome; COVID19, coronavirus disease 2019; GAM, generalized additive model; $W H O$, World Health Organization; $L A I$, leaf area index; OxCGRT, Oxford COVID-19 Government Response Tracker; $S D$, standard deviation; $I Q R$, interquartile range; $R R$, relative risk; $C I s$, confidence intervals

Supplementary Information The online version contains supplementary material available at https://doi.org/10.1007/s11356-021-16500-y.

Author contribution XY: Conceptualization, methodology, writingoriginal draft. ZW: Methodology, data curation, writing — original draft. XW: Methodology, Writing - review and editing. XZ: Methodology, writing - review and editing. LW: Methodology, writing - review and editing. ZL: Conceptualization, writing-review and editing. ZJ: Conceptualization, supervision, project administration, writing-review and editing.

Funding This work was supported by the National Key Research and Development Program of China (2020YFC0849200) and the Key Joint Project for Data Center of the National Natural Science Foundation of China and Guangdong Provincial Government (U1611264).

Availability of data and materials The datasets used and/or analyzed during the current study are available from the corresponding author on reasonable request.

\section{Declarations}

Ethics approval and consent to participate Not applicable 
Consent for publication Not applicable

Competing interests The authors declare no competing interests

\section{References}

Altamimi A, Ahmed AE (2020) Climate factors and incidence of Middle East respiratory syndrome coronavirus. J Infect Public Health 13: 704-708

Anastasiou OE, Hüsing A, Korth J, Theodoropoulos F, Taube C, Jöckel KH, Stang A, Dittmer U (2021) Seasonality of non-SARS, nonMERS coronaviruses and the impact of meteorological factors. Pathogens 10:187

Bashir MF, Ma BJ, Bilal et al (2020) Correlation between environmental pollution indicators and COVID-19 pandemic: a brief study in Californian context. Environ Res 187:109652

Cai QC, Lu J, Xu QF, Guo Q, Xu DZ, Sun QW, Yang H, Zhao GM, Jiang QW (2007) Influence of meteorological factors and air pollution on the outbreak of severe acute respiratory syndrome. Public Health 121:258-265

Candido DS, Claro IM, de Jesus JG, Souza WM, Moreira FRR, Dellicour S, Mellan TA, du Plessis L, Pereira RHM, Sales FCS, Manuli ER, Thézé J, Almeida L, Menezes MT, Voloch CM, Fumagalli MJ, Coletti TM, da Silva CAM, Ramundo MS, Amorim MR, Hoeltgebaum HH, Mishra S, Gill MS, Carvalho LM, Buss LF, Prete CA Jr, Ashworth J, Nakaya HI, Peixoto PS, Brady OJ, Nicholls SM, Tanuri A, Rossi ÁD, Braga CKV, Gerber AL, de C. Guimarães AP, Gaburo N Jr, Alencar CS, Ferreira ACS, Lima CX, Levi JE, Granato C, Ferreira GM, Francisco RS Jr, Granja F, Garcia MT, Moretti ML, Perroud MW Jr, Castiñeiras TMPP, Lazari CS, Hill SC, de Souza Santos AA, Simeoni CL, Forato J, Sposito AC, Schreiber AZ, Santos MNN, de Sá CZ, Souza RP, Resende-Moreira LC, Teixeira MM, Hubner J, Leme PAF, Moreira RG, Nogueira ML, Brazil-UK Centre for Arbovirus Discovery, Diagnosis, Genomics and Epidemiology (CADDE) Genomic Network, Ferguson NM, Costa SF, Proenca-Modena JL, Vasconcelos ATR, Bhatt S, Lemey P, Wu CH, Rambaut A, Loman NJ, Aguiar RS, Pybus OG, Sabino EC, Faria NR (2020) Evolution and epidemic spread of SARS-CoV-2 in Brazil. Science. 369(6508):1255-1260

Casanova LM, Jeon S, Rutala WA, Weber DJ, Sobsey MD (2010) Effects of air temperature and relative humidity on coronavirus survival on surfaces. Appl Environ Microbiol 76:2712-2717

Cecily Jane M (2009) Promoting children's mental, emotional and social health through contact with nature: a model. Health Educ 109:522543

Chan KH, Peiris JS, Lam SY et al (2011) The effects of temperature and relative humidity on the viability of the SARS coronavirus. Adv Virol 2011:734690-734697

Chen Y, Xie SD (2013)Long-term trends and characteristics of visibility in two megacities in southwest China: Chengdu and Chongqing. $\mathrm{J}$ Air Waste Manage Assoc 63:1058-1069

Chen B, Liang H, Yuan X, et al (2020) Roles of meteorological conditions in COVID-19 transmission on a worldwide scale. medRxiv 2020:20037168v1.

Cherrie M, Clemens T, Colandrea C, Feng Z, Webb DJ, Weller RB, Dibben C (2013) Ultraviolet A radiation and COVID-19 deaths in the USA with replication studies in England and Italy. Br J Dermatol 2013:363-370. https://doi.org/10.1111/bjd.20093

Coccia M (2020a) Factors determining the diffusion of COVID-19 and suggested strategy to prevent future accelerated viral infectivity similar to COVID. Sci Total Environ 729:138474
Coccia M (2020b) An index to quantify environmental risk of exposure to future epidemics of the COVID-19 and similar viral agents: theory and practice. Environ Res 191:110155

Coccia M (2020c) How (un)sustainable environments are related to the diffusion of COVID-19: the relation between coronavirus disease 2019, air pollution, wind resource and energy. Sustainability 12 : 9709

Coccia M (2021a) High health expenditures and low exposure of population to air pollution as critical factors that can reduce fatality rate in COVID-19 pandemic crisis: a global analysis. Environ Res 199: 111339

Coccia M (2021b) The effects of atmospheric stability with low wind speed and of air pollution on the accelerated transmission dynamics of COVID-19. Int J Environ Stud 78:1-27

Coccia M (2021c) Effects of the spread of COVID-19 on public health of polluted cities: results of the first wave for explaining the dejà vu in the second wave of COVID-19 pandemic and epidemics of future vital agents. Environ Sci Pollut Res Int 28(15):19147-19154

Coccia M (2021d) How do low wind speeds and high levels of air pollution support the spread of COVID-19? Atmos Pollut Res 12(1): $437-445$

Coccia M (2021e) Preparedness of countries to face Covid-19 pandemic crisis: Strategic positioning and underlying structural factors to support strategies of prevention of pandemic threats. Environ Res 203: 111678

Coccia M (2021f) The relation between length of lockdown, numbers of infected people and deaths of Covid-19, and economic growth of countries: lessons learned to cope with future pandemics similar to Covid-19. Sci Total Environ 775:145801 (Available online 12 February 2021)

Coccia M (2021g) Pandemic prevention: lessons from COVID-19. Encyclopedia 1:433-444

Diao Y, Kodera S, Anzai D, Gomez-Tames J, Rashed EA, Hirata A (2020) Influence of population density, temperature, and absolute humidity on spread and decay durations of COVID-19: a comparative study of scenarios in China, England, Germany, and Japan. One Health 12:100203

Domingo JL, Marquès M, Rovira J (2020) Influence of airborne transmission of SARS-CoV-2 on COVID-19 pandemic. A review. Environ Res 188:109861

du Prel JB, Puppe W, Gröndahl B, Knuf M, Weigl JAI, Schaaff F, Schmitt HJ (2009) Are meteorological parameters associated with acute respiratory tract infections? Clin Infect Dis 49:861-868

Eccles R (2002) An explanation for the seasonality of acute upper respiratory tract viral infections. Acta Otolaryngol 122:183-191

Frontera A, Martin C, Vlachos K, Sgubin G (2020) Regional air pollution persistence links to COVID-19 infection zoning. J Inf Secur 81:318356

Gardner EG, Kelton D, Poljak Z, van Kerkhove M, von Dobschuetz S, Greer AL (2019) A case-crossover analysis of the impact of weather on primary cases of Middle East respiratory syndrome. BMC Infect Dis 19:113

Greatorex JS, Digard P, Curran MD, Moynihan R, Wensley H, Wreghitt T, Varsani H, Garcia F, Enstone J, Nguyen-van-Tam JS (2011) Survival of influenza A (H1N1) on materials found in households: implications for infection control. PLoS One 6:e27932

Hamre D, Procknow JJ (1966) A new virus isolated from the human respiratory tract. Proc Soc Exp Biol Med 121:190-193

Hannah R, Ortiz-Ospina E, Beltekian D, et al (2020) Coronavirus pandemic (COVID-19). https://ourworldindata.org/coronavirus. (accessed on 9 May 2021)

Haque SE, Rahman M (2020) Association between temperature, humidity, and COVID-19 outbreaks in Bangladesh. Environ Sci Pol 114: 253-255

Horne BD, Joy EA, Hofmann MG, Gesteland PH, Cannon JB, Lefler JS, Blagev DP, Korgenski EK, Torosyan N, Hansen GI, Kartchner D, 
Pope CA III (2018)Short-term elevation of fine particulate matter air pollution and acute lower respiratory infection. Am J Respir Crit Care Med 198:759-766

Irfan M, Ikram M, Ahmad M et al (2021) Does temperature matter for COVID-19 transmissibility? Evidence across Pakistani provinces. Environ Sci Pollut Res 18:1-15

Islam N, Bukhari Q, Jameel Y, Shabnam S, Erzurumluoglu AM, Siddique MA, Massaro JM, D'Agostino RB Sr (2021)COVID-19 and climatic factors: a global analysis. Environ Res 193:110355

Kim G (2016) Assessing urban forest structure, ecosystem services, and economic benefits on vacant land. Sustainability 8:679

Kwon T, Gaudreault NN, Richt JA (2021) Environmental stability of SARS-CoV-2 on different types of surfaces under indoor and seasonal climate conditions. Pathogens 10:227

Leung K, Shum MH, Leung GM et al (2021) Early transmissibility assessment of the N501Y mutant strains of SARS-CoV-2 in the United Kingdom, October to November 2020. Euro Surveill 26(1): 2002106

Li Y, Wang X, Nair H (2020) Global seasonality of human seasonal coronaviruses: a clue for postpandemic circulating season of severe acute respiratory syndrome coronavirus 2? J Infect Dis 222:1090 1097

Ma Y, Zhao Y, Liu J, He X, Wang B, Fu S, Yan J, Niu J, Zhou J, Luo B (2020) Effects of temperature variation and humidity on the death of COVID-19 in Wuhan, China. Sci Total Environ 724:138226

National Bureau of Statistics of the People's Republic of China (2005) China Statistical Yearbook 2004. http://www.stats.gov.cn/tjsj/ndsj/ yb2004-c/indexch.htm. (accessed on 9 May 2021)

National Health Commission of the People's Republic of China (2003) Report of SARS.http://www.nhc.gov.cn/wjw/zcjd/201304/ 65baea2466a3467b984e89f16f7dd301.shtml. (accessed on 4 April 2021)

Notari A (2021) Temperature dependence of COVID-19 transmission. Sci Total Environ 763:144390

Pan J, Yao Y, Liu Z, Meng X, Ji JS, Qiu Y, Wang W, Zhang L, Wang W, Kan H (2021) Warmer weather unlikely to reduce the COVID-19 transmission: an ecological study in 202 locations in 8 countries. Sci Total Environ 753:142272

Pica N, Bouvier NM (2012) Environmental factors affecting the transmission of respiratory viruses. Curr Opin Virol 2:90-95

Poirier C, Luo W, Majumder MS, Liu D, Mandl KD, Mooring TA, Santillana M (2020) The role of environmental factors on transmission rates of the COVID-19 outbreak: an initial assessment in two spatial scales. Sci Rep 10:17002

Qi H, Xiao S, Shi R, Ward MP, Chen Y, Tu W, Su Q, Wang W, Wang X, Zhang Z (2020)COVID-19 transmission in Mainland China is associated with temperature and humidity: a time-series analysis. Sci Total Environ 728:138778

Rahimi NR, Fouladi-Fard R, Aali R, Shahryari A, Rezaali M, Ghafouri Y, Ghalhari MR, Asadi-Ghalhari M, Farzinnia B, Conti Gea O, Fiore M (2021) Bidirectional association between COVID-19 and the environment: a systematic review. Environ Res 194:110692

Rosario DKA, Mutz YS, Bernardes PC, Conte-Junior CA (2020) Relationship between COVID-19 and weather: case study in a tropical country. Int J Hyg Environ Health 229:113587

Salah B, Dinh Xuan AT, Fouilladieu JL, Lockhart A, Regnard J (1988) Nasal mucociliary transport in healthy subjects is slower when breathing dry air. Eur Respir J 1:852-855

Sarkodie SA, Owusu PA (2020) Impact of meteorological factors on COVID-19 pandemic: Evidence from top 20 countries with confirmed cases. Environ Res 191:110101

Seitz J, Escobedo F (2014) Urban forests in Florida: trees control stormwater runoff and improve water quality. University of Florida, Institute of Food and Agricultural Sciences. IFAS Extension Publication FOR184.
Shen L, Zhao T, Wang H, Liu J, Bai Y, Kong S, Zheng H, Zhu Y, Shu Z (2021) Importance of meteorology in air pollution events during the city lockdown for COVID-19 in Hubei Province, Central China. Sci Total Environ 754:142227

Srivastava A (2021)COVID-19 and air pollution and meteorology-an intricate relationship: a review. Chemosphere 263:128297

Su S, Wong G, Shi W, Liu J, Lai ACK, Zhou J, Liu W, Bi Y, Gao GF (2016) Epidemiology, genetic recombination, and pathogenesis of coronaviruses. Trends Microbiol 24:490-502

Tan J, Mu L, Huang J, Yu S, Chen B, Yin J (2005) An initial investigation of the association between the SARS outbreak and weather: with the view of the environmental temperature and its variation. J Epidemiol Community Health 59:186-192

Tang X, Wu C, Li X, Song Y, Yao X, Wu X, Duan Y, Zhang H, Wang Y, Qian Z, Cui J, Lu J (2020) On the origin and continuing evolution of SARS-CoV-2. Natl Sci Rev 7(6):1012-1023

Thomas Y, Vogel G, Wunderli W, Suter P, Witschi M, Koch D, Tapparel C, Kaiser L (2008) Survival of influenza virus on banknotes. Appl Environ Microbiol 74:3002-3007

Ulrich RS (1984) View through a window may influence recovery from surgery. Science 224:420-421

United Nations (2019) World population prospects 2019. https:// population.un.org/wpp/Download/Standard/Population/.(accessed on 9 May 2021)

University of Oxford (2020)COVID-19 government response tracker. https://www.bsg.ox.ac.uk/research/research-projects/covid-19government-response-tracker. (accessed on 25 June 2021)

van Den Berg AE, Custers MH (2011) Gardening promotes neuroendocrine and affective restoration from stress. J Health Psychol 16:3-11

van Doremalen N, Bushmaker T, Munster VJ (2013) Stability of Middle East respiratory syndrome coronavirus (MERS-CoV) under different environmental conditions. Euro Surveill 18:20590

Wevers BA, Lia V (2009) Recently discovered human coronaviruses. Clin Lab Med 29:715-724

World Health Organization (2015) Summary of probable SARS cases with onset of illness from 1 November 2002 to 31 July 2003. https://www.who.int/publications/m/item/summary-of-probablesars-cases-with-onset-of-illness-from-1-november-2002-to-31-july2003. (accessed on 9 May 2021)

World Health Organization. (2021a)MERS-CoV disease outbreak news. https://www.who.int/csr/don/archive/disease/coronavirus infections/en/. (accessed on 9 May 2021)

World Health Organization. (2021b) Disease outbreak news (DONs). https://www.who.int/emergencies/disease-outbreak-news/1. (accessed on 9 May 2021)

World Health Organization. (2021c) Severe acute respiratory syndrome (SARS). https://www.who.int/csr/don/archive/disease/severe acute_respiratory_syndrome/en/. (accessed on 9 May 2021)

Wu Y, Jing W, Liu J, Ma Q, Yuan J, Wang Y, du M, Liu M (2020) Effects of temperature and humidity on the daily new cases and new deaths of COVID-19 in 166 countries. Sci Total Environ 729: 139051

Xie J, Zhu Y (2020) Association between ambient temperature and COVID-19 infection in 122 cities from China. Sci Total Environ $724: 138201$

Xie J, Teng J, Fan Y, Xie R, Shen A (2019) The short-term effects of air pollutants on hospitalizations for respiratory disease in Hefei. China. Int J Biometeorol 63:315-326

Xu Q, Li X, Wang S, Wang C, Huang F, Gao Q, Wu L, Tao L, Guo J, Wang W, Guo X (2016) Fine particulate air pollution and hospital emergency room visits for respiratory disease in urban areas in Beijing, China, in 2013. PLoS One 11:e0153099

$\mathrm{Xu} \mathrm{K}$, Cui K, Young, et al. (2020) Impact of the COVID-19 event on air quality in central China. Aerosol Air Qual Res 20:915-929

Xu B, Wang J, Li Z, Xu C, Liao Y, Hu M, Yang J, Lai S, Wang L, Yang W (2021) Seasonal association between viral causes of hospitalised 
acute lower respiratory infections and meteorological factors in China: a retrospective study. Lancet Planet Health 5:e154-e163

Yang W, Elankumaran S, Marr LC (2012) Relationship between humidity and influenza A viability in droplets and implications for influenza's seasonality. PLoS One 7:e46789

You Y, Pan S (2020) Urban vegetation slows down the spread of coronavirus disease (COVID-19) in the United States. Geophys Res Lett 47:e2020GL089286
Zhao S, Lou J, Cao L et al (2021) Quantifying the transmission advantage associated with N501Y substitution of SARS-CoV-2 in the UK: an early data-driven analysis. J Travel Med 28(2):taab011

Zitkovic M (2008) Managing green spaces for urban biodiversity. In: Countdown 2010 Secretariat. IUCN Regional Office for Europe, Belgium

Publisher's note Springer Nature remains neutral with regard to jurisdictional claims in published maps and institutional affiliations. 